\title{
Inheritance of drought resistance related traits in two crosses of groundnut (Arachis hypogaea L.)
}

\author{
H. D. Upadhyaya $\cdot$ Shivali Sharma • \\ Sube Singh $\cdot$ Murari Singh
}

Received: 27 January 2010/ Accepted: 14 September 2010/Published online: 26 September 2010

(C) Springer Science+Business Media B.V. 2010

\begin{abstract}
Groundnut (Arachis hypogaea L.) is an important oilseed crop grown in more than 100 countries across wide range of environments. Frequent occurrence of drought is one of the limiting factors adversely affecting groundnut productivity, especially in rainfed areas, and hence genotypes having high water use efficiency (WUE) under limited available water need to be developed. In groundnut, WUE is correlated with SPAD chlorophyll meter reading (SCMR) and specific leaf area (SLA). These two traits, SCMR and SLA, can be used as surrogate traits for selecting for WUE. In order to improve SCMR and SLA, and in turn WUE in groundnut, a good knowledge of the genetic system controlling the expressions of these traits is essential for the selection of the most appropriate and efficient breeding procedure. The present investigation was conducted to determine the gene action controlling the inheritance of SCMR and SLA in two crosses, ICG $7243 \times$ ICG 9418 and ICG $6766 \times$
\end{abstract}

H. D. Upadhyaya $(\bowtie) \cdot S$. Sharma · S. Singh

International Crops Research Institute for the Semi Arid

Tropics (ICRISAT), Patancheru, Hyderabad 502324,

$\mathrm{AP}$, India

e-mail: h.upadhyaya@cgiar.org

\section{Singh}

Department of Mathematics and Statistics, Concordia University, 1455 De Maisonneuve Blvd West, Montreal, QC H3G 2J5, Canada
Chico, and their reciprocals. Six generations of each cross $\left(\mathrm{P}_{1}, \mathrm{P}_{2}, \mathrm{~F}_{1}, \mathrm{~F}_{2}, \mathrm{BC}_{1} \mathrm{P}_{1}\right.$, and $\left.\mathrm{BC}_{1} \mathrm{P}_{2}\right)$ were evaluated for SCMR and SLA at two stages of the crop growth viz., 60 and 80 days after sowing (DAS). For SCMR at 80 DAS, additive effects were important in both the crosses whereas predominance of dominance effects with duplicate epistasis was observed for SCMR at 60 DAS and SLA at both stages in both the crosses. Predominance of additive effect for SCMR at 80 DAS suggested effective selection could be practiced even in early generations whereas for SCMR at 60 DAS and SLA at both stages in both crosses, it would be better to defer selection to later generations. Further, recording of SCMR and SLA should be done between 60 and 80 DAS for screening the germplasm lines for drought tolerance.

Keywords Arachis hypogaea - Groundnut · Additive gene effects · Epistasis - SCMR - SLA

\section{Introduction}

Groundnut (Arachis hypogaea L.) is valued throughout the world for high quality edible oil and easily digestible protein in its seeds. Globally, it is cultivated on 23.4 million ha with annual production of 34.9 million metric tons and an average yield of 1.5 tons ha ${ }^{-1}$ (Food and Agriculture Organization 2007). 
Groundnut is grown extensively in about 108 countries with over two-thirds of the global output coming from seasonally rainfed areas of tropical, subtropical and warm regions of the world. The productivity of groundnut in rainfed areas is considerably lower than the global average and still lower as compared to its productivity in the better-endowed regions where it is grown on commercial scale. Availability of water is considered to be the major yield limiting factor in groundnut, not only in rainfed areas where drought occurs at regular intervals, but also in those regions where it is grown commercially. Therefore, breeding drought tolerant cultivars is an important objective in most groundnut genetic enhancement programs. However, the non-availability of reliable and rapid tools to screen drought related traits is the major obstacle in the progress of genetic improvement for drought tolerance in groundnut (Rucker et al. 1995). The model presented by Passioura (1986) outlined yield as a function of water transpired (T), water use efficiency (WUE) and harvest index. Numerous studies have noted considerable variation in WUE among plants including groundnut (Martin and Thorstenson 1988; Virgona et al. 1990; Ehdaie et al. 1991; Nageswara Rao et al. 1993; Ebdon et al. 1998; Shashidhar 2002); however, WUE is not an easy trait to measure and thus difficult to use as a selection criterion in breeding programs. Recently, a number of easily measurable traits having high correlation with WUE have been identified as surrogates. One among them is carbon isotope discrimination, which shows consistent negative correlation with WUE in a wide range of crop species including groundnut (Farquhar et al. 1982; Hubick et al. 1986; Nageswara Rao et al. 1993; Wright et al. 1988; 1994; Martin et al. 1999; Shashidhar 2002). However, its utility as a selection criterion has been limited as this requires specific facilities for carbon isotope discrimination analysis and is hardly available in groundnut growing developing countries. Moreover, it is expensive and not feasible when large number of germplasm accessions and segregating populations are to be analyzed (Lal et al. 2005).

Traits which have practical advantage over carbon isotope discrimination as a surrogate for WUE, are specific leaf area (SLA) and soil plant analysis development (SPAD) chlorophyll meter reading (SCMR). Wright et al. (1994), Nageswara Rao and Wright (1994) and Jayalakshmi et al. (1999) reported positive correlations between SLA and carbon isotope discrimination, and a negative correlation with WUE over a wide range of cultivars and environments in groundnut, suggesting that SLA can be used as a surrogate measure of WUE in groundnut. The SCMR has been used effectively to determine leaf nitrogen content non-destructively in a number of crops including maize (Chapman and Barreto 1997), barley (Araus et al. 1997), tobacco (Mackown and Sutton 1998) and groundnut (Nageswara Rao et al. 2001). Nageswara Rao et al. (2001) reported significant and high interrelationship among SLA, SLN (Specific leaf nitrogen), and SCMR. Bindu Madhava et al. (2003) reported a strong positive relationship between SCMR and WUE in groundnut. Nageswara Rao et al. (2001) and Bindu Madhava et al. (2003) suggested that SCMR could be used as a reliable and rapid measure to identify genotypes with low SLA or high SLN (and hence high WUE) in groundnut. Upadhyaya (2005) used SCMR and SLA as surrogate traits for assessing WUE in groundnut mini core germplasm collection (Upadhyaya et al. 2002) and reported negative correlation between SCMR and SLA.

Our previous work on evaluation of mini core collection of groundnut for SCMR and SLA has shown significant repeatable genotypic variation among 184 entries (85 hypogaea, 58 vulgaris, 37 fastigiata, two peruviana, and one each of aequitoriana and hirsuta) for both the traits measured at two stages (Upadhyaya 2005). The broad sense heritability estimates have been reported to be high for SCMR and medium for SLA, suggesting that genetic variation and heritabilities are high enough in groundnut to effectively select for SCMR and SLA as surrogates for WUE. Jayalakshmi et al. (1999) reported high estimate (0.50) of narrow sense heritability for SLA. The exploitation of genetic variability through breeding requires a good knowledge of the genetic system controlling the expression of these traits. There are only four published reports on the genetic control of SLA in groundnut (Jayalakshmi et al. 1999; Nigam et al. 2001; Lal et al. 2005; Suriharn et al. 2005) while there is only one such study for SCMR in groundnut (Lal et al. 2005). Based on diallel analysis, Jayalakshmi et al. (1999) and Lal et al. (2005) and based upon generation mean analysis Suriharn et al. (2005) and Nigam et al. (2001) reported predominance of additive gene effect in the control of SLA in groundnut. Lal et al. (2005) reported preponderance of additive gene action in the inheritance of SCMR. 
The primary objective of this study was to estimate the relative importance of additive and non-additive gene effects in controlling the variation in SCMR and SLA at two developmental stages in the two crosses of groundnut. The estimation of gene effects of drought related traits at various stages would be helpful in formulating appropriate breeding strategies for developing groundnut varieties capable of performing better under water limiting environments.

\section{Materials and methods}

\section{Experimental materials}

Four genotypes, ICG 6766, ICG 7243, ICG 9418 and Chico were selected for the present study based on the screening of groundnut mini core for drought related traits (SCMR and SLA) during 2001 rainy and 2001-02 post-rainy seasons (Upadhyaya 2005). ICG 6766 (subsp hypogaea var hypogaea) and ICG 7243 (subsp hypogaea var hypogaea) are germplasm lines from the USA having high SCMR and low SLA values. Chico is an early maturing Spanish (subsp fastigiata var vulgaris) germplasm line (Bailey and Hammons 1975) while ICG 9418 (subsp fastigiata var vulgaris) is a landrace from Martinique. Both the lines have low SCMR and high SLA (Table 2). These genotypes represented the spectrum of available variation for SCMR and SLA in the groundnut mini core germplasm collection. Two crosses, ICG $7243 \times$ ICG 9418 and ICG $6766 \times$ Chico and their reciprocals were made in the glasshouse during 2002 rainy season. The $F_{1} s$ and reciprocals were grown in the glasshouse and crossed with each of the parents to generate backcross generations $\left(\mathrm{BC}_{1} \mathrm{P}_{1}\right.$ and $\left.\mathrm{BC}_{1} \mathrm{P}_{2}\right)$ during 2002-2003 post-rainy season. Because of the limited number of seeds, fresh $\mathrm{F}_{1} \mathrm{~s}$ and backcrosses were made in the glasshouse during 2003 rainy season and $\mathrm{F}_{1} \mathrm{~s}$ were advanced to $\mathrm{F}_{2}$ generations. The parents $\left(\mathrm{P}_{1}\right.$ and $\left.\mathrm{P}_{2}\right), \mathrm{F}_{1} \mathrm{~s}, \mathrm{~F}_{2} \mathrm{~s}, \mathrm{BC}_{1} \mathrm{P}_{1}$ and $\mathrm{BC}_{1} \mathrm{P}_{2}$ of the two direct and two reciprocal crosses formed the experimental material for the study.

\section{Experimental design and observations}

The experimental material was evaluated in a split-plot design with three replications in the Alfisol (alfisolPatancheru Soil Series; Udic Rhodustolf) precision field at the International Crops Research Institute for the Semi-Arid Tropics (ICRISAT), Patancheru, India during 2003-2004 post-rainy season. Crosses were assigned to main plots and generations to subplots within each main plot. The plot size was a 3-m long single row on a ridge in a ridge-furrow system for parents and $F_{1}$ hybrids, two rows for backcross generations and 10 rows for $F_{2}$ populations. Row to row distance was $60 \mathrm{~cm}$ and plant-to-plant distance within a row was $10 \mathrm{~cm}$. The experiment received $60 \mathrm{~kg} \mathrm{ha}^{-1} \mathrm{P}_{2} \mathrm{O}_{5}$ as basal dose, $400 \mathrm{~kg} \mathrm{ha}^{-1}$ gypsum at the time of flowering (50 days after sowing DAS) and 12 irrigations of $50 \mathrm{~mm}$ water each. Seeds were treated with ethrel@0.5\% (2-chloroethylphosphonic acid) before sowing in order to avoid the possible effects of post harvest seed dormancy. Sowing was done by hand and care was taken to ensure uniform depth of planting at $5 \mathrm{~cm}$ depth. The crop was protected from weeds, diseases, and insect pests. The SPAD chlorophyll meter (SPAD-502, Minolta Crop., Ramsey, NJ, USA) readings (SCMR) were recorded at equivalent cumulative thermal times (CTT, measured in degree days, ${ }^{\circ} \mathrm{Cd}, 10^{\circ} \mathrm{C}$ as base temperature) (Rao et al. 1992) of $1000^{\circ} \mathrm{Cd}$ (equivalent to $60 \mathrm{DAS}$ in the rainy season) and $1270^{\circ} \mathrm{Cd}$ (equivalent to $80 \mathrm{DAS}$ in the rainy season at ICRISAT). The CTT was estimated by the following formula:

$\mathrm{CTT}\left({ }^{\circ} \mathrm{Cd}\right)=\sum_{P}^{H}\left(\frac{T_{\max }+T_{\min }}{2}\right)-T_{\text {base }}$

where $\mathrm{T}_{\max }=$ daily maximum temperature, $\mathrm{T}_{\min }=$ daily minimum temperature, $\mathrm{T}_{\text {base }}=$ mean base temperature for groundnut, $\mathrm{P}=$ planting date, and $\mathrm{H}=$ harvest date.

Two SCMRs were recorded on each of the four leaflets of the tetrafoliate leaf. Only one fully expanded second or third leaf from the apex of the main axis of all the available plants was used to record the SCMR at 60 and 80 days after sowing (Nageswara Rao et al. 2001). While recording the SCMR, care was taken to ensure that the sensor of SPAD meter fully covered the leaf lamina and that the interference from veins and midribs was avoided. After recording the SCMR, the detached leaves were processed by soaking in water for $2 \mathrm{~h}$ to bring to full turgor for SLA measurement. The leaf area of the four leaflets was measured with a leaf area meter (LI-COR Area Meter Model 3000, LI-COR Inc., 
Lincoln, NE, USA) after which the leaves were oven dried at $80^{\circ} \mathrm{C}$ for at least $48 \mathrm{~h}$ to determine the leaf dry weight. SLA was calculated as follows:

$\mathrm{SLA}=$ Leaf area $\left(\mathrm{cm}^{2}\right) /$ Leaf dry weight $(\mathrm{g})$.

Generation mean analysis

Analysis of variance was conducted for SCMR and SLA using GenStat 10.0 mixed linear model assuming replications as random and generations as fixed factors. Data on SCMR and SLA recorded at two stages were examined for the segregation pattern in $\mathrm{F}_{2}$ and when data did not fit to qualitative gene inheritance, they were subjected to quantitative genetic analysis. For each of the two crosses, individual plant data on SCMR and SLA were summarized as means, variances, ranges and estimated standard errors of the means for each of their six generations: $\mathrm{P}_{1}, \mathrm{P}_{2}, \mathrm{~F}_{1}, \mathrm{~F}_{2}, \mathrm{BC}_{1} \mathrm{P}_{1}$ and $\mathrm{BC}_{1} \mathrm{P}_{2}$ as well as of their reciprocal generations. The means and ranges of $F_{1}, F_{2}$ and backcross generations were compared with their reciprocals to examine the maternal effect, if any. In case of non-significant reciprocal differences, the data were pooled for the generation means analysis. Means of SCMR and SLA recorded at two different stages and between six generations in each cross were compared using $t$ test. The generation means were used to perform simple scaling test (Mather and Jinks 1982) and fitting digenic interaction models. The scaling test is based on the assumption that generation means depend only on the additive and dominance effects. To test these assumptions, four types of tests based on statistics: A, B, C, and D were used. The joint scaling test (Cavalli 1952) as described by Mather and Jinks (1982) was used to obtain information on the nature of gene effects involved in the genetic control of drought-related traits. The parameters estimated were mean $(\mathrm{m})$, pooled additive [d] and pooled dominance [h] gene effects and three types of gene interactions, pooled additive $\times$ additive [i], pooled additive $\times$ dominance [j] and pooled dominance $\times$ dominance [1] epistatic effects. These parameters were estimated by weighted least square method. The purpose of using weights is to account for differential precision with which means of different generations are estimated by virtue of different sample size. The weights were calculated as the inverse of variance of generation means. All possible 32 models developed from including or excluding one or more of the five parameters $(\mathrm{d}, \mathrm{h}, \mathrm{i}, \mathrm{j}$, and $\mathrm{l})$ with $\mathrm{m}$ were fitted using a general linear model set-up in Genstat software (Payne 2009). First of all those models which showed insignificant deviation compared with a tabulated chisquare $(P>0.05)$ were considered for selection. Of these, the model that showed the smallest deviation was selected. In case of nearly equal mean deviation for two models, a model with smaller number of parameters were considered and also the sequence of model terms for selection was taken as $\mathrm{m}, \mathrm{d}, \mathrm{h}, \mathrm{i}, \mathrm{j}$ and $\mathrm{l}$. The standard errors for each of the six parameters were estimated and the significance of each parameter was tested using $t$ test.

For the models selected, we evaluated the relative importance of the gene effects in terms of sums of squares due to each parameter adjusted for the effects of the remaining parameters of the model. Thus, these contributions are representing the direct effects of the genetic parameters under consideration. This approach differs from that of Nigam et al. (2001) where contribution of the parameters were considered in the sequential sum of squares, in which case the contribution of the parameters following the chosen parameters would get ignored. These direct contributions are presented relative to the all such contributions.

Mid-parent heterosis and inbreeding depression were estimated for individual crosses as the percent deviation of the mean $F_{1}$ value from the mid-parent value and its significance was tested using $t$ test. Additive and dominance genetic variances and narrow-sense heritability were estimated by the methods of Warner (1952). Environmental variance was estimated as per the formula of Wright (1968). The minimum number of effective factors controlling SCMR and SLA was estimated by the methods of Wright (1921), Mather and Jinks (1982) and Lande (1981). All the effective factor formulae assume that segregating genes for SCMR and SLA are located in one parent, all genes have equal effect and no linkage, and there is absence of dominance, epistasis and genotype $\times$ environment effects (Wright 1968).

\section{Results and discussion}

Cytoplasmic effects

The ANOVA revealed significant differences for mean values of both SCMR and SLA at 60 and 80 DAS among generations in both the crosses (data not 
shown). Reciprocal differences consistent with cytoplasmic inheritance were not detected for SCMR and SLA at 60 and 80 DAS in both the crosses, ICG 7243 $\times$ ICG 9418 and ICG $6766 \times$ Chico (Table 1), suggesting that no maternal factors are involved in their inheritance. Though the $F_{2}$ generation of the cross ICG $6766 \times$ Chico had significant reciprocal differences for SCMR (43.90 in $\mathrm{F}_{2}$ and 46.60 in reciprocal $F_{2}$ ) and SLA (168.79 in $F_{2}$ and 157.39 in reciprocal $\mathrm{F}_{2}$ ) at $80 \mathrm{DAS}$, it is of only statistical significance as the $F_{1}$ and back cross generations of the same cross did not support the maternal inheritance of SCMR and SLA. Lal et al. (2005), however, reported strong influence of maternal parents in the inheritance of SCMR and SLA in a study involving six-parent diallel. Since all other generations except $\mathrm{F}_{2}$ in the cross ICG $6766 \times$ Chico did not show reciprocal differences, it was assumed that maternal factors did not influence the above traits in both the crosses and the data of respective generations were pooled for further analysis.

Developmental stage effects

An examination of mean values of different generations in each cross showed that phenotypic values of
SCMR and SLA differed significantly at two developmental stages, except for SLA in ICG 9418, SCMR and SLA in Chico, and SLA in $\mathrm{F}_{1}$ and $\mathrm{BC}_{1} \mathrm{P}_{2}$ of the cross ICG $6766 \times$ Chico (Table 2). The mean of SLA in all the generations decreased significantly when measured at 80 DAS except in the cases where there were no significant differences while SCMR increased significantly as compared to means observed at 60 DAS. The mean SCMR and SLA of Chico did not differ across the stages of measurement. However, ICG 7243 and ICG 6766 showed higher value of SCMR and reduced value of SLA at 80 DAS as compared with 60 DAS. This trend was observed across the generations in both the crosses. However, the pattern was almost same at both the stages. This shows that SCMR and SLA should be recorded between 60 and 80 DAS for screening the germplasm lines for drought tolerance. This period corresponds with the pod filling stage which is most sensitive to drought in groundnut (Nageswara Rao et al. 1985, 1993).

Means and variances

Means and their standard errors, variance and range for SCMR and SLA in six generations of two crosses

Table 1 Reciprocal effects in different generations of two groundnut crosses for SCMR and SLA

\begin{tabular}{|c|c|c|c|c|c|c|c|}
\hline \multirow[t]{2}{*}{ Character } & \multirow[t]{2}{*}{ Generation } & \multicolumn{3}{|c|}{ ICG $7243 \times$ ICG 9418} & \multicolumn{3}{|c|}{ ICG $6766 \times$ Chico } \\
\hline & & Normal & Reciprocal & $t$ test & Normal & Reciprocal & $t$ test \\
\hline \multirow[t]{4}{*}{ SCMR at 60 DAS } & $\mathrm{F}_{1}$ & $43.90 \pm 0.751$ & $44.47 \pm 0.597$ & ns & $43.37 \pm 0.612$ & $43.99 \pm 0.542$ & ns \\
\hline & $\mathrm{F}_{2}$ & $44.64 \pm 0.285$ & $44.30 \pm 0.268$ & ns & $41.62 \pm 0.197$ & $42.59 \pm 0.233$ & ns \\
\hline & $\mathrm{BC}_{1} \mathrm{P}_{1}$ & $46.90 \pm 0.961$ & $46.02 \pm 0.511$ & ns & $38.88 \pm 0.906$ & $40.64 \pm 0.537$ & ns \\
\hline & $\mathrm{BC}_{1} \mathrm{P}_{2}$ & $42.01 \pm 0.961$ & $43.54 \pm 0.820$ & ns & $44.06 \pm 0.600$ & $43.52 \pm 0.652$ & ns \\
\hline \multirow[t]{4}{*}{ SCMR at $80 \mathrm{DAS}$} & $\mathrm{F}_{1}$ & $50.90 \pm 0.404$ & $49.46 \pm 0.754$ & ns & $46.74 \pm 0.958$ & $46.44 \pm 0.611$ & ns \\
\hline & $\mathrm{F}_{2}$ & $48.20 \pm 0.321$ & $48.22 \pm 0.267$ & $\mathrm{~ns}$ & $43.90 \pm 0.266$ & $46.60 \pm 0.309$ & $-6.64 * *$ \\
\hline & $\mathrm{BC}_{1} \mathrm{P}_{1}$ & $51.23 \pm 1.195$ & $50.10 \pm 0.455$ & ns & $43.53 \pm 0.826$ & $42.47 \pm 0.855$ & ns \\
\hline & $\mathrm{BC}_{1} \mathrm{P}_{2}$ & $44.07 \pm 0.931$ & $45.91 \pm 0.900$ & ns & $47.53 \pm 0.827$ & $47.83 \pm 0.776$ & ns \\
\hline \multirow[t]{4}{*}{ SLA at 60 DAS } & $\mathrm{F}_{1}$ & $156.89 \pm 5.853$ & $157.81 \pm 2.730$ & $\mathrm{~ns}$ & $159.18 \pm 2.208$ & $156.65 \pm 2.223$ & ns \\
\hline & $\mathrm{F}_{2}$ & $155.83 \pm 1.335$ & $156.29 \pm 1.327$ & ns & $169.24 \pm 1.307$ & $166.08 \pm 1.426$ & ns \\
\hline & $\mathrm{BC}_{1} \mathrm{P}_{1}$ & $152.35 \pm 3.089$ & $153.22 \pm 2.990$ & ns & $194.23 \pm 4.307$ & $180.28 \pm 3.831$ & ns \\
\hline & $\mathrm{BC}_{1} \mathrm{P}_{2}$ & $163.04 \pm 5.690$ & $153.85 \pm 3.672$ & ns & $165.24 \pm 3.018$ & $162.07 \pm 2.592$ & $\mathrm{~ns}$ \\
\hline \multirow[t]{4}{*}{ SLA at $80 \mathrm{DAS}$} & $\mathrm{F}_{1}$ & $155.64 \pm 6.097$ & $147.04 \pm 2.158$ & ns & $154.08 \pm 2.670$ & $157.11 \pm 1.786$ & ns \\
\hline & $\mathrm{F}_{2}$ & $146.93 \pm 1.600$ & $151.00 \pm 1.516$ & ns & $168.79 \pm 1.483$ & $157.39 \pm 1.463$ & $5.47 * *$ \\
\hline & $\mathrm{BC}_{1} \mathrm{P}_{1}$ & $135.99 \pm 2.964$ & $138.20 \pm 2.733$ & ns & $177.10 \pm 4.346$ & $185.29 \pm 3.981$ & ns \\
\hline & $\mathrm{BC}_{1} \mathrm{P}_{2}$ & $144.98 \pm 3.408$ & $144.25 \pm 3.981$ & ns & $157.72 \pm 2.939$ & $154.92 \pm 3.473$ & $\mathrm{~ns}$ \\
\hline
\end{tabular}

$n s$ non-significant at $P \leq 0.05,{ }^{* *}$ significant at $P \leq 0.01$ 
Table 2 Phenotypic means (pooled) of different generations for SLA and SCMR at two stages in two crosses of groundnut

\begin{tabular}{|c|c|c|c|c|c|c|c|}
\hline Cross & Generation & SCMR at 60 DAS & SCMR at 80 DAS & $t$ test & SLA at 60 DAS & SLA at 80 DAS & $t$ test \\
\hline \multirow[t]{6}{*}{ ICG $7243 \times$ ICG 9418} & $\mathrm{P}_{1}(\mathrm{ICG} 7243)$ & $47.09 \pm 0.744$ & $50.37 \pm 0.851$ & 0.012 & $149.13 \pm 1.934$ & $129.95 \pm 3.815$ & $<0.001$ \\
\hline & $\mathrm{P}_{2}$ (ICG9418) & $39.23 \pm 0.486$ & $43.56 \pm 0.882$ & $<0.001$ & $173.29 \pm 3.277$ & $174.29 \pm 2.960$ & ns \\
\hline & $\mathrm{F}_{1}$ & $44.34 \pm 0.487$ & $49.78 \pm 0.605$ & $<0.001$ & $157.61 \pm 2.405$ & $148.95 \pm 2.231$ & 0.012 \\
\hline & $\mathrm{F}_{2}$ & $44.45 \pm 0.195$ & $48.21 \pm 0.206$ & $<0.001$ & $156.08 \pm 0.944$ & $149.30 \pm 1.110$ & $<0.001$ \\
\hline & $\mathrm{BC}_{1} \mathrm{P}_{1}$ & $46.30 \pm 0.463$ & $50.49 \pm 0.509$ & $<0.001$ & $152.91 \pm 2.206$ & $137.48 \pm 2.066$ & $<0.001$ \\
\hline & $\mathrm{BC}_{1} \mathrm{P}_{2}$ & $43.02 \pm 0.635$ & $45.28 \pm 0.680$ & 0.018 & $157.00 \pm 3.144$ & $144.50 \pm 2.834$ & 0.004 \\
\hline \multirow[t]{6}{*}{ ICG $6766 \times$ Chico } & $\mathrm{P}_{1}$ (ICG 6766) & $45.24 \pm 0.523$ & $50.01 \pm 0.475$ & $<0.001$ & $133.63 \pm 1.136$ & $122.07 \pm 2.297$ & $<0.001$ \\
\hline & $\mathrm{P}_{2}$ (Chico) & $39.77 \pm 0.452$ & $40.37 \pm 0.608$ & ns & $187.55 \pm 3.238$ & $187.62 \pm 2.323$ & ns \\
\hline & $\mathrm{F}_{1}$ & $43.73 \pm 0.402$ & $46.56 \pm 0.523$ & $<0.001$ & $157.70 \pm 1.579$ & $155.85 \pm 1.520$ & ns \\
\hline & $\mathrm{F}_{2}$ & $42.02 \pm 0.151$ & $44.91 \pm 0.209$ & $<0.001$ & $168.00 \pm 0.973$ & $164.49 \pm 1.100$ & 0.017 \\
\hline & $\mathrm{BC}_{1} \mathrm{P}_{1}$ & $43.80 \pm 0.440$ & $47.53 \pm 0.566$ & $<0.001$ & $163.71 \pm 1.994$ & $156.46 \pm 2.237$ & 0.018 \\
\hline & $\mathrm{BC}_{1} \mathrm{P}_{2}$ & $40.06 \pm 0.477$ & $42.77 \pm 0.618$ & $<0.001$ & $185.08 \pm 3.020$ & $182.35 \pm 3.015$ & ns \\
\hline
\end{tabular}

ns non significant $P \leq 0.05$

based on pooled data are presented in Table 3. The parental genotype ICG 7243 had high WUE followed by ICG 6766 as indicated by their high SCMR and low SLA values at 60 and 80 DAS. Mean values of SCMR and SLA recorded for ICG 7243 (47.09, 50.37, 149.13 and 129.95) and ICG 6766 (45.24, $50.01,133.63,122.07)$ in the experiment were comparable with the values recorded for ICG 7243 $(46.13,48.55,154.1,148.5)$ and ICG 6766 (44.42, $48.96,152.09,139.77)$ in earlier studies during postrainy seasons in 2001-02 (Upadhyaya 2005). Both Chico and ICG 9418 had low SCMR and high SLA values at 60 and 80 DAS suggesting their poor WUE.

The means for SCMR and SLA recorded at 60 and 80 DAS were compared among six generations in both the crosses (Table 3 ). In the cross ICG $7243 \times$ ICG 9418, the mean SCMR of $\mathrm{F}_{1}, \mathrm{~F}_{2}$ and $\mathrm{BC}_{1} \mathrm{P}_{2}$ at 60 DAS tended to be near the mid parent value and the mean SCMR of $\mathrm{BC}_{1} \mathrm{P}_{1}$ was close to its recurrent parent, indicating the importance of additive gene action in the inheritance of SCMR at 60 DAS. At 80 DAS, the mean SCMR of the $\mathrm{F}_{1}$ and $\mathrm{BC}_{1} \mathrm{P}_{1}$ was close to the high SCMR parent (ICG 7243) and $F_{2}$ mean rested between mid parent value and high SCMR parent suggesting the more pronounced role of dominance effect of high SCMR parent (ICG 7243) in controlling SCMR at 80 DAS. In ICG $6766 \times$ Chico, at 60 DAS, mean SCMR of the $\mathrm{F}_{1}$ was close to high SCMR parent (ICG 6766), but $\mathrm{F}_{2}$ mean tended to be near the mid parent value. Means of the backcross generations were observed close to the means of their respective recurrent parents. At 80 DAS, the mean SLA of $F_{1}$ and $\mathrm{BC}_{1} \mathrm{P}_{1}$ rested between mid parent and high SCMR parent and $\mathrm{F}_{2}$ tended to be close to the mid parent. These results indicate the more pronounced role of dominance effect and a less pronounced effect of additive effect of high SCMR parent (ICG 6766) at 60 and 80 DAS. The mean SLA of $\mathrm{F}_{1}, \mathrm{~F}_{2}, \mathrm{BC}_{1} \mathrm{P}_{1}$ and $\mathrm{BC}_{1} \mathrm{P}_{2}$ generations was lower than the mid parent value in ICG $7243 \times$ ICG 9418 at both the stages whereas in ICG $6766 \times$ Chico, the mean SLA of $\mathrm{F}_{1}$ and $\mathrm{BC}_{1} \mathrm{P}_{1}$ was close to the mid parent value and the mean SLA of $\mathrm{F}_{2}$ and $\mathrm{BC}_{1} \mathrm{P}_{2}$ was higher than the mid parent, reflecting different gene actions operating in the inheritance of SLA in these crosses. These results suggest partial dominance of low SLA (ICG 7243) in the cross ICG $7243 \times$ ICG 9418 and the importance of additive gene effects controlling SLA in the cross ICG $6766 \times$ Chico.

The magnitude of variation for SCMR and SLA at 60 and 80 DAS in the segregating generations was much higher than that observed in the corresponding parents and $F_{1}$ generations in both the crosses. The maximum variability was observed in $F_{2}$ generation for SCMR and SLA at both the stages in both crosses. The SCMR of the $F_{2}$ plants ranged from 27.3-55.4 at 60 DAS and 35.3-61.7 at 80 DAS in ICG $7243 \times$ ICG 9418, and 29.0-53.1 at 60 DAS and 28.0-59.0 at 80 DAS in the cross ICG $6766 \times$ Chico (Table 3 ). In $\mathrm{F}_{2}$ generation, the range of SLA at 60 DAS was 108.3-247.8 in ICG $7243 \times$ ICG 9418 and 101.1-225.5 in ICG $6766 \times$ Chico while SLA at 


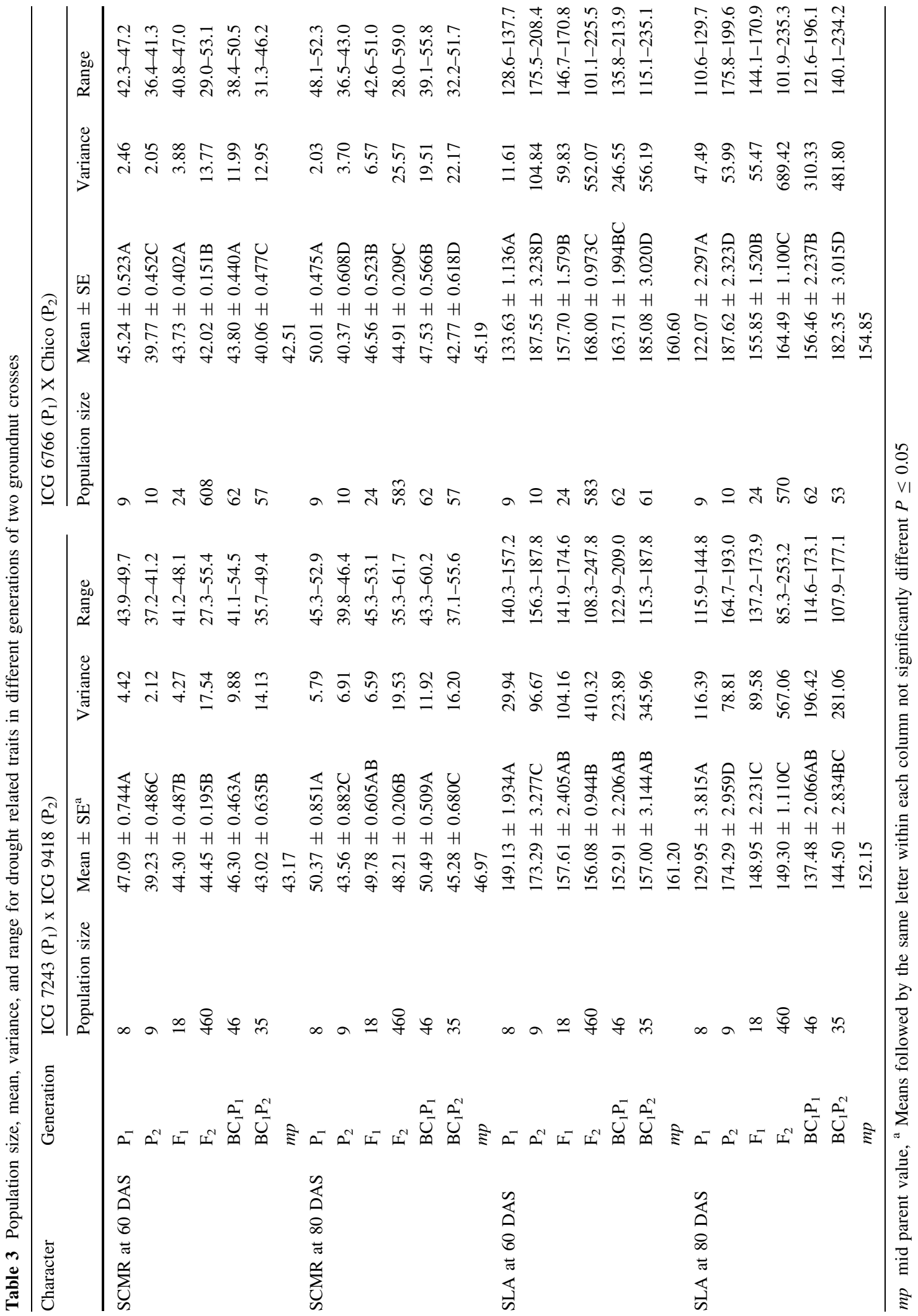


80 DAS ranged 85.3-253.2 in former cross and 101.9-235.3 in the latter cross. At 80 DAS, the range of variability was increased by $28.6 \%$ and $7.2 \%$ for SCMR and SLA, respectively in the cross ICG 6766 $\times$ Chico, but was decreased by $6.2 \%$ for SCMR and increased by $20.4 \%$ for SLA in the cross ICG $7243 \times$ ICG 9418. Appearance of plants exceeding the limits of both the parents in $\mathrm{F}_{2}$ (transgressive segregants) and backcross generations indicated dispersal of genes among the parents for both the traits: thus the present study didn't fulfill the assumption for calculating the minimum number of factors controlling SCMR and SLA and provided the biased estimates (data not given). Since all $F_{2}$ and backcross generations had normal distribution without the presence of distinct bimodal peaks (non-significant skew and kurtosis), $\chi^{2}$ test was not performed and the traits were treated as quantitative.

Heterosis and inbreeding depression

The estimates of heterosis over mid-parent and inbreeding depression for SCMR and SLA at two stages in two crosses were found non-significant (data not given).

\section{Generation mean analysis}

Generation mean analysis indicated different modes of inheritance for SCMR and SLA in the two crosses (Table 4). The regression analysis tested different parameters to find the best fit model to explain genetic control of SCMR and SLA at two stages in both the crosses. Mean effects [m] were highly significant for SCMR and SLA in both the crosses at both stages indicating quantitative inheritance of the traits studied. Additive effects were important for SCMR and SLA in both the crosses at both stages (Table 4). They were positive for SCMR and negative for SLA in the cross ICG $7243 \times$ ICG 9418 and positive for SLA and negative for SCMR in the cross ICG $6766 \times$ Chico at both the stages. Negative sign of additive effect merely reflects which of the parents is chosen as $\mathrm{P}_{1}$ and has no genetic consequences. The dominance effects were important for SCMR and SLA at both the stages in the cross ICG $7243 \times$ ICG 9418 and for SCMR at 60 DAS and SLA at both the stages in the cross ICG $6766 \times$ Chico. These results indicate differential importance of dominance effects

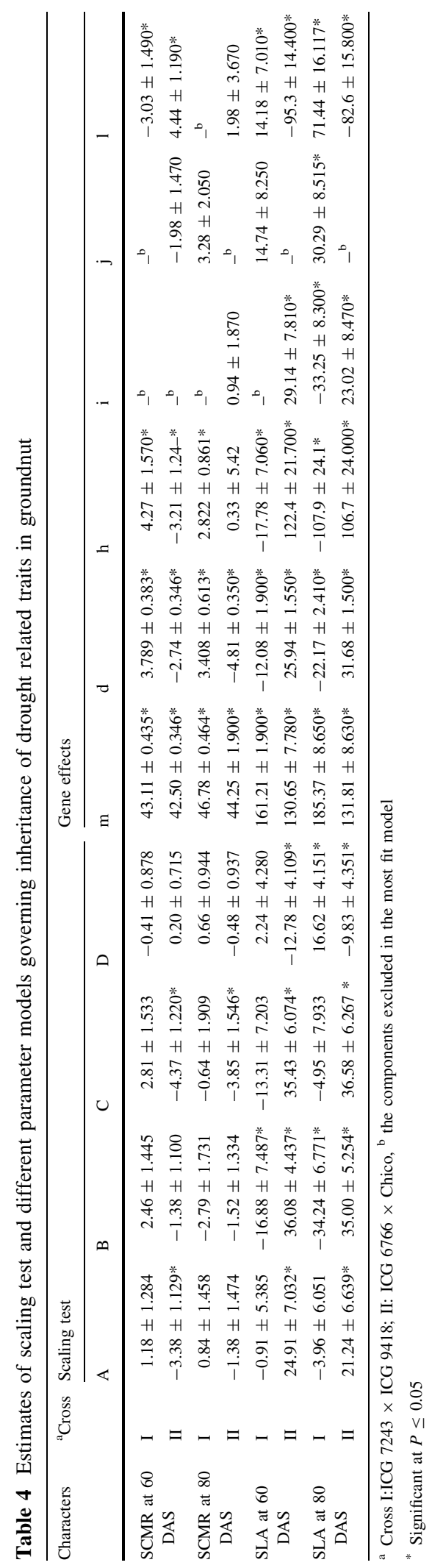


for SCMR in these two crosses. The sign of dominance effects is a function of $F_{1}$ generation mean value in relation to the mid parent value and it indicates which parent is contributing to the dominance effects. For SCMR at both the stage, the dominance effects were significant and positive in the cross ICG $7243 \times$ ICG 9418 but were significant and negative for SCMR at 60 DAS in the cross ICG 6766 $\times$ Chico. These results indicated that in the cross ICG $7243 \times$ ICG 9418, $F_{1}$ are more like the increasing parent i.e. ICG 7243 as dominance is controlled by the parent having alleles responsible for high value of the trait whereas in the cross ICG $6766 \times$ Chico, the dominance effects are contributed by the genes from Chico for SCMR at 60 DAS. For SLA, dominance effects were significant and greater than the additive effects indicating over dominance for SLA in both the crosses at both stages. For SLA, the dominance effects in the cross ICG $7243 \times$ ICG 9418 at two stages were contributed by the parent having alleles responsible for low value of the trait, i.e. ICG 7243 and was dominant over the other parent ICG 9418 (having increasing effects of alleles). The dominance effects in the cross ICG $6766 \times$ Chico were contributed by the genes from Chico (Table 4), as indicated by the sign of the dominance effect $[\mathrm{h}]$.

The result of fitting the models indicates that epistasis was present for SCMR and SLA in the two crosses at both stages (Table 4), although the significance of interactions varies with the trait, cross and the stage. For SCMR at 60 DAS, 'l' type of epistatic interaction was important in both the crosses while at $80 \mathrm{DAS}$, the epistatic interactions were nonsignificant for both the crosses. For SLA in the cross ICG $7243 \times$ ICG 9418, 1 type of epistatic effect was important at 60 DAS and all the three types of epistatic effects, i $\left(-33.25 \pm 8.300_{*}\right), j \quad(30.29 \pm$ $\left.8.515^{*}\right)$ and $1\left(71.44 \pm 16.117^{*}\right)$ were important at 80 DAS in this cross while in ICG $6766 \times$ Chico, only two types of interactions, $i$ and 1 were important at both the stages (Table 4). The genes controlling SCMR at 60 DAS and SLA at 60 and 80 DAS in both the crosses showed duplicate interactions as reflected by opposite sign of $\mathrm{h}$ and 1 in these cases (Table 4) (Mather and Jinks 1982).

The variability accounted for by the different estimated effects varied in both the crosses for SCMR and SLA (Table 5). Additive effects, d, accounted for the largest portion of genetic variability for SCMR and SLA in both the crosses at both stages. The largest contribution of the dominance effect was for SCMR $(13.58 \%)$ and SLA (13.15\%) at 80 DAS in the cross ICG $7243 \times$ ICG 9418 . The i type epistatic effects, which are fixable, accounted for $10.50 \%$ variability and $\mathrm{j}$ type epistatic effect accounted for $8.28 \%$ variability for SLA at 80 DAS in the cross ICG $7243 \times$ ICG 9418. The largest contribution of the 1 type epistatic effect was for SCMR at 60 DAS in the cross ICG $6766 \times$ Chico (Table 5). In earlier studies, Lal et al. (2005) reported predominance of additive gene effects for SCMR.

The significance of additive effects contributing to SCMR at 80 DAS in both the crosses suggests that effective selection for SCMR could be practiced even in the early generations in both the crosses at 80 DAS.

The magnitude of heterosis was low for SCMR and SLA at both stages in both crosses. Low magnitude of heterosis for SCMR at 80 DAS in both crosses is due to the preponderance of additive gene effects, whereas in rest of the cases, this is because

Table 5 Variability accounted for by the different components for SCMR and SLA at two stages in two groundnut crosses

\begin{tabular}{|c|c|c|c|c|c|c|}
\hline \multirow[t]{2}{*}{ Cross } & \multirow[t]{2}{*}{ Trait } & \multicolumn{5}{|c|}{ Genetic components } \\
\hline & & d & $\mathrm{h}$ & $\mathrm{i}$ & $\mathrm{j}$ & 1 \\
\hline \multirow[t]{4}{*}{ ICG $7243 \times$ ICG 9418} & SCMR at 60 DAS & 88.99 & 6.71 & - & - & 3.76 \\
\hline & SCMR at 80 DAS & 82.34 & 13.58 & - & - & - \\
\hline & SLA at 60 DAS & 74.35 & 11.70 & - & 5.90 & 7.55 \\
\hline & SLA at 80 DAS & 55.22 & 13.15 & 10.50 & 8.28 & 12.86 \\
\hline \multirow[t]{4}{*}{ ICG $6766 \times$ Chico } & SCMR at 60 DAS & 73.62 & 7.88 & - & 2.15 & 16.26 \\
\hline & SCMR at 80 DAS & 99.71 & 0.00 & 0.13 & - & 0.15 \\
\hline & SLA at 60 DAS & 75.37 & 8.54 & 3.75 & - & 11.82 \\
\hline & SLA at 80 DAS & 88.62 & 3.92 & 1.46 & - & 5.44 \\
\hline
\end{tabular}


the sign of [h] and [1] are opposite to each other, i.e. duplicate type of non-allelic interaction is present, which reduces the estimates of heterosis in these cases. As the magnitude of heterosis and inbreeding depression is small for SCMR at 80 DAS where additive gene effects are important, selection for this trait in early generations would be effective. For SCMR at 60 DAS and SLA at both stages in both crosses, it would be better to defer selection to the later generations.

The genetic complexity of developmental behaviour of physiological traits like SLA and SCMR largely enhanced the difficulties in genetic analysis. In the present study, genetic characteristics of physiological traits exhibited great complexity during development, which was represented by the variation of magnitude and significance of the genetic variances. One possible reason might be that polygene system of quantitative traits could have specific expression pattern at different developmental periods. Furthermore, various developmental periods might be controlled by different loci of the polygene system. $\mathrm{Wu}$ and Stettler (1994) reported that different QTLs could modify the growth of the Populus. The other reason might be that different position leaves would have effects on the variation of the traits of drought due to different environmental conditions of sunshine, temperature, humidity and so on.

The heritability (broad sense) of SCMR and SLA was appreciably higher at both the stages in both the crosses (Table 6) suggesting that a large portion of total variation could be attributed to genetic factors involving additive as well as non-additive effects. The SCMR and SLA showed high broad sense heritability, which is in agreement with the results obtained by Upadhyaya (2005). This suggests that simple breeding methods such as hybridization and selection for genetic improvement of these traits may be contemplated. The magnitude of narrow sense heritability was higher in the cross ICG $7243 \times$ ICG 9418 for SCMR whereas broad-sense heritability of this trait was comparatively higher in the cross ICG $6766 \times$ Chico, suggesting preponderance of additive genetic variance for SCMR in the former cross and dominance variance in the latter cross. For SLA, narrow sense heritability was high at both the stages for both the crosses, except ICG $7243 \times$ ICG 9418 at 80 DAS, indicating preponderance of additive genetic variance in the inheritance of SLA. As a general rule, traits defined by a small number of genes show high heritability in early generations, permitting the fixation of distinct genotypes by using a small number of selfing generations (Anand and Torrie 1963).

Quantitative traits like SCMR and SLA are expected to be influenced to a large extent by environmental effects. Environmental variances, however, accounted for only 20-21\% for SCMR at 60 DAS, 16-33\% for SCMR at 80 DAS, $11-19 \%$ for SLA at 60 DAS and $8-17 \%$ for SLA 80 DAS in both the crosses. In a previous study, the estimates of environmental variance were in this range for both the traits (Upadhyaya 2005), suggesting the importance of genetic effects in the inheritance of these traits.

\section{Conclusions}

Overall, in the present investigation, it can be inferred that SCMR and SLA should be recorded between 60 DAS and 80 DAS, which represent the pod filling

Table 6 Variance components and narrow $\left(\mathrm{h}_{\mathrm{ns}}^{2}\right)$ and broad sense $\left(\mathrm{h}_{\mathrm{bs}}^{2}\right)$ heritability estimates for SCMR and SLA in two groundnut crosses

\begin{tabular}{|c|c|c|c|c|c|c|c|c|}
\hline \multirow[t]{2}{*}{ Estimates } & \multicolumn{4}{|c|}{ ICG $7243 \times$ ICG 9418} & \multicolumn{4}{|c|}{ ICG $6766 \times$ Chico } \\
\hline & SCMR 60 & SCMR 80 & SLA 60 & SLA 80 & SCMR 60 & SCMR 80 & SLA 60 & SLA 80 \\
\hline$\sigma_{\mathrm{g}}^{2}$ & 13.94 & 13.10 & 333.40 & 472.13 & 10.97 & 21.47 & 493.37 & 637.07 \\
\hline$\sigma_{\mathrm{d}}^{2}$ & 11.07 & 10.94 & 250.79 & 656.64 & 2.60 & 9.46 & 301.50 & 586.10 \\
\hline$\sigma_{\mathrm{h}}^{2}$ & 2.87 & 2.16 & 82.61 & -184.51 & 8.37 & 12.01 & 191.87 & 50.97 \\
\hline$\sigma_{\mathrm{e}}^{2}$ & 3.60 & 6.43 & 76.92 & 94.93 & 2.80 & 4.10 & 58.73 & 52.33 \\
\hline$\sigma_{\mathrm{P}}^{2}$ & 17.54 & 19.53 & 410.32 & 567.06 & 13.77 & 25.57 & 552.07 & 689.40 \\
\hline $\mathrm{h}_{\mathrm{ns}}^{2}$ & 0.63 & 0.56 & 0.61 & - & 0.19 & 0.37 & 0.55 & 0.85 \\
\hline $\mathrm{h}_{\mathrm{bs}}^{2}$ & 0.80 & 0.67 & 0.81 & 0.83 & 0.80 & 0.84 & 0.89 & 0.92 \\
\hline
\end{tabular}


stage and which is the most sensitive to drought. The SCMR and SLA data recorded at this stage would help to identify the drought tolerant lines and hence to alleviate the drought stress, particularly in the semi arid tropics. Regarding genetic control of SCMR and SLA, duplicate epistasis has been observed in the inheritance of SCMR at 60 DAS in both the crosses and for SLA in both the crosses at both the stages. For SCMR at 80 DAS, the preponderance of additive gene action has been observed in both the crosses. Predominance of additive effect for SCMR at 80 DAS suggested that effective selection could be practiced even in early generations. The importance of dominance effect with duplicate epistasis for SCMR at 60 DAS and SLA at both stages in both crosses indicated that selection and breeding procedures should be modified to exploit this type of nonadditive genetic variance by delaying the selection to later generations.

\section{References}

Anand SC, Torrie JH (1963) Heritability of yield and other traits interrelationships among traits in $\mathrm{F}_{3}$ and $\mathrm{F}_{4}$ generations of three soybeans crosses. Crop Sci 3:508-511

Araus JL, Bort J, Caccareli S, Grando S (1997) Relationship between leaf structure and carbon isotope discrimination in field grown barley. Plant Physiol Biochem 35:533-541

Bailey WK, Hammons RO (1975) Registration of Chico peanut germplasm. Crop Sci 15:105

Bindu Madhava H, Sheshshayee MS, Shankar AG, Prasad TG, Udaykumar M (2003) Use of SPAD chlorophyll meter to assess transpiration efficiency of peanut. In: Cruickshank AW et al. (ed). Breeding of drought resistant peanuts. ACIAR Proceedings No. 112. Proceedings of a collaborative review meeting, Hyderabad, Andhra Pradesh, India, ACIAR, Canberrra, Australia.25-27 Feb 2002 pp 3-9

Cavalli LL (1952) An analysis of linkage in quantitative inheritance. In: Rieve ECR, Waddington $\mathrm{CH}$ (eds) Quantitative Inheritance. HMSO, London, pp 135-144

Chapman SC, Barreto HJ (1997) Using a chlorophyll meter to estimate specific leaf nitrogen of tropical maize during vegetative growth. Agron J 89:557-562

Ebdon JS, Petrovic AM, Dawson TE (1998) Relationship between carbon isotope discrimination, water use efficiency and evapotranspiration in Kentucky bluegrass. Crop Sci 38:157-162

Ehdaie B, Hall AE, Farquhar GD, Nguyen HT, Waines JG (1991) Water use efficiency and carbon isotope discrimination in wheat. Crop Sci 31:1282-1288

Farquhar GD, O'Leary MH, Berry JA (1982) On the relationship between carbon isotope discrimination and the intercellular carbon dioxide concentration in leaves. Aust J Plant Physiol 9:121-137
Food and Agriculture Organization (2007) http://www/FAO. ORG. FAOSTAT database

Hubick KT, Farquhar GD, Shorter R (1986) Correlation between water use efficiency and carbon isotope discrimination in diverse peanut (Arachis) germplasm. Aust $\mathrm{J}$ Plant Physiol 13:803-816

Jayalakshmi V, Rajareddy C, Reddy PV, Nageswara Rao RC (1999) Genetic analysis of carbon isotope discrimination and specific leaf area in groundnut (Arachis hypogaea L.). J Oilseeds Res 16:1-5

Lal C, Hariprasanna K, Rathnakumar AL, Basu MS, Gor HK, Chikani BM (2005) Identification of water use efficient groundnut genotypes for rainfed situations through leaf morpho-physiological traits. IAN 25:4-7

Lande R (1981) The minimum number of genes contributing to quantitative variation between and within populations. Genet 99:541-553

Mackown CT, Sutton TG (1998) Using early season leaf traits to predict nitrogen sufficiency of burley tobacco. Agron J 90:21-27

Martin B, Thorstenson YR (1988) Stable carbon isotope discrimination $\left(\delta^{13} \mathrm{C}\right)$, water use efficiency, and biomass productivity of Lycopersicon esculentum, Lycopersicon pennellii and the $\mathrm{F}_{1}$ hybrid. Plant Physiol 88:213-217

Martin B, Tauer CG, Lin RK (1999) Carbon isotope discrimination as a tool to improve water use efficiency in tomato. Crop Sci 39:1775-1783

Mather K, Jinks JL (1982) Biometrical Genetics, 2nd edn. Chapman and Hall, London, p 382

Nageswara Rao RC, Wright GC (1994) Stability of the relationship between specific leaf area and carbon isotope discrimination across environments in peanut. Crop Sci 34:98-103

Nageswara Rao RC, Sardar Singh, Sivakumar MVK, Srivastava KL, Williams JH (1985) Effect of moisture deficit at different growth stages of peanut. I. Yield responses. Agron J 77:782-786

Nageswara Rao RC, Williams JH, Wadia KDR, Hubick KT, Farquhar GD (1993) Crop growth, water use efficiency and carbon isotope discrimination in groundnut (Arachis hypogaea L.) genotypes under end of season drought conditions. Ann Appl Biol 122:357-367

Nageswara Rao RC, Talwar HS, Wright GC (2001) Rapid assessment of specific leaf area and leaf nitrogen in peanut (Arachis hypogaea L.) using a chlorophyll meter. J Agron Crop Science 186:175-182

Nigam SN, Upadhyaya HD, Chandra S, Nageswara Rao RC, Wright GC, Reddy AGS (2001) Gene effects for specific leaf area and harvest index in three crosses of groundnut (Arachis hypogaea). Ann Appl Biol 139:301-306

Passioura JB (1986) Resistance to drought and salinity: Avenues for improvement. Aust J Plant Physiol 13:91-201

Payne RW (2009) The guide to GenStat ${ }^{\circledR}$ release 12, Part 2: Statistics. VSN International, 5 The Waterhouse, Waterhouse Street, Hemel Hempstead, Hertfordshire HP1 1ES, UK

Rao MJV, Nigam SN, Huda AKS (1992) The thermal time concept as a selection criterion for earliness in peanut. Peanut Sci 19:7-10

Rucker KS, Kvien CK, Holbrook CC, Wood JE (1995) Identification of peanut genotypes with improved drought avoidance traits. Peanut Sci 22:14-18 
Shashidhar G (2002) Screening diverse germplasm lines of groundnut (Arachis hypogaea L.) for genetic variability in water use efficiency and total dry matter based on stable isotopes and RAPD. M.Sc. (Agric) Thesis submitted to University of Agricultural Sciences, Bangalore

Suriharn B, Patanothai A, Jogloy S (2005) Gene effects for specific leaf area and harvest index in peanut (Arachis hypogaea L.). Asian J Plant Sci 4:667-672

Upadhyaya HD (2005) Variability for drought resistance related traits in the mini core collection of peanut. Crop Sci 45:1432-1440

Upadhyaya HD, Bramel PJ, Ortiz R, Sube Singh (2002) Developing a mini core of peanut for utilization of genetic resources. Crop Sci 42:2150-2156

Virgona JM, Hubick KT, Rawson HM, Farquhar GD, Downes RW (1990) Genotypic variation in transpiration efficiency, carbon isotope discrimination and carbon allocation during early growth in sunflower. Aust J Plant Physiol 17:207-214
Warner JN (1952) A method of estimating heritability. Agron J 44:427-430

Wright S (1921) System of mating. Genetics 6:111-178

Wright S (1968) The genetics of quantitative variability. In: Wright S (ed) Evolution and genetics of populations. Vol I. Genetic and biometric foundations. University of Chicago Press, Chicago

Wright GC, Hubick KT, Farquhar GD (1988) Discrimination in carbon isotopes of leaves correlates with water use efficiency of field grown peanut varieties. Aust J Plant Physiol 15:815-825

Wright GC, Nageswara Rao RC, Farquhar GD (1994) Water use efficiency and carbon isotope discrimination in peanut under water deficit conditions. Crop Sci 34:92-97

Wu R, Stettler RE (1994) Quantitative genetics of growth and development in Populos.I. A three generation comparison of tree architecture during the first two years of growth. Theor Appl Genet 89:1046-1054 